\title{
The "Equity Waltz" in Canada: Whiteness and the informal realities of racism in education
}

\author{
Paul R. Carr, Youngstown State University, Ohio \\ prcarr@ysu.edu
}

\begin{abstract}
Canada has long perceived itself to be a country in which multiculturalism, and a concomitant respect for diversity, is a unique and defining feature of its identity. Although Canada is a de facto multicultural country, owing to its rapidly evolving demography and the explicit notion of multiculturalism enshrined in its Constitution, there remains a plethora of problems and issues related to equity, diversity and human rights. This paper explores the context and impact of racism in education within a framework that acknowledges and critically positions the predominance of Whiteness. The salience of identity, therefore, is a primary consideration to understanding how marginalized groups face systemic barriers in education. The concluding analysis sheds light on the educational policy process, and focuses on the notion of accountability for anti-racism and social justice in education within a time of neoliberal reforms. The paper is critical of the lack of attention, resources and comprehensive plans in place to ensure that all students benefit from a more holistic education that includes a focus on social justice.
\end{abstract}

\section{Introduction}

Canada has long perceived itself to be a country in which multiculturalism, and a concomitant respect for diversity, is a unique and defining feature of its identity (Reitz \& Banerjee, 2006). Moreover, Canada has often been regarded as a country that has more openly and effectively embraced pluralism than other societies ${ }^{\mathrm{i}}$. Although Canada is a de facto multicultural country, owing to its rapidly evolving demography and the explicit notion of multiculturalism enshrined in its Constitution, there remains a plethora of problems and issues related to equity, diversity and human rights (Carr \& Lund, 2007). A major focus to any discussion of diversity necessarily concerns social justice, and acknowledging its existence has been a contentious and arduous process (Fleras, 2002; Dei, Karumanchery, \& Karumanchery-Luik, 2004).

As governments become more intertwined and submerged in neoliberal policies, there is an obvious shifting from somewhat explicit social justice approaches toward less direct concepts (citizenship, character and civic education), or some other standardsbased program, as a response to widespread, systemic social concerns, such as racism (Hill, 2003; McLaren, 2007). Lauder, Brown, Dillabough and Halsey (2006) further frame the arguments around the potential for development and social change through education within a globalized economic context. As Banks et al. (2005) have outlined, being critically aware of, and engaged with, diversity needs to become a fundamental disposition and competency for students in addition to the other commonly-designated

Journal of Contemporary Issues in Education, 2008, 3(2), pp. 4-23.

ISSN 1718-4770 (C) 2008 University of Alberta

http://ejournals.library.ualberta.ca/index.php/JCIE 
priorities in education. Thus, addressing the core concern of neo-liberalism and globalization is considered an integral feature to countering the apolitical nature of education, and, moreover, to enhancing a critical approach to social justice (Kincheloe, 2008).

The naming of, and focus on, marginalization in, what is commonly thought to be, a democratic society may be extremely nuanced and under-played, which can lead to conflict, given the lack of validation of diverse identities (Banks, 2008). Governments have become increasingly skilled at coding language so as to present an inclusive and progressive face while perpetuating the status quo (Lund, 2006). The metaphor of the "equity waltz" contained in the title of this paper symbolizes the back-and-forth, almost hypnotic, seemingly effortless motion, floating on the dance-floor, which could also be applied to the way racism is approached within the Canadian context: dynamic, considered fluid and something that is constantly being addressed, but it is easily swept aside in order to focus on the meshing of bodies, and generally understood to be lighthearted rather than systemically debilitating. The premise of White power and privilege, which is explored herein, is that racial discrimination, within education as well as within the societal context, is not merely the work of a "few bad apples" but has a broader, more far-reaching underpinning that, ultimately, relates to inequitable power relations (Carr \& Lund, 2007).

This paper explores the relevance of race, racialization and racism in education. White power and privilege, and the lived experiences, perceptions and identities of marginalized groups, provide a backdrop to the analysis. One important consideration is that the intent, or articulation of the problem, must be considered within the context of the actual outcome in terms of equity in education; in other words, the cleavage between the rhetoric and reality of racism must critically interrogated. The paper contains five sections: 1) framing the context for discussing race and identity in Canada; 2) Whiteness as a conceptual model for understanding the racial problematic in education; 3) defining anti-racism in Canada; 4) analyzing anti-racism programs in education, with a focus on Ontario; and 5) considerations and perspectives for policy development and research, including the introduction of a social justice accountability framework.

\section{Framing the context for discussing race and identity in Canada}

As the world becomes more globalized, more people, representing a multitude of ethnocultural, racial, linguistic, religious and other minority groups, are migrating, seeking exile, emigrating and leading lives that were previously unheard of in terms of studying, living and working in diverse locations (Vincent, 2003). Canada is a dynamic reflection of this trend (Reitz \& Banerjee, 2006). Canada is a country of immigrants, despite the historical foundation known as the "two founding nations" (Great Britain and France), which has been increasingly contested over the years. Significantly, the Aboriginal peoples claimed Canada, and North America, as their ancestral homeland for 10,00020,000 years before the arrival of the Europeans some five hundred years ago (Royal Commission on Aboriginal Peoples, 1996).

The following sections contextualize the diversity inherent in, and permeating, the Canadian state and identity, which serve as a fundamental precursor to discussing educational policy development. It should be noted that this paper elucidates only some 
of the groups forming the diverse demography of Canada; at the same time, it is openly acknowledged that identity is extremely complex, dynamic and problematic (Vincent, 2003). Not all people of one origin or another experience a phenomenon the same way, which frames the notion of identity being socially constructed (James, 2003). Similarly, the intersectionality of identity infers that there are several components - including race, ethnicity, gender, class, sexual orientation, physical ability, religion, language, family, etc. - that work concurrently to shape one's reality. Therefore, in discussing identity, it is important to provide the cautionary note that the objective here is not to stigmatize or essentialize groups but, rather, to elucidate the problematic of racism in society. It is equally pertinent to highlight that this paper deals with the social manifestation of identity (and race), and does not advocate for a scientific or biological interpretation of race. Since racism exists in society, I argue that it is critical to understand how and why it manifests itself, and, moreover, what can be done to diminish and eliminate it. Given the visible and invisible inequities in society, an examination of the role of identity seems to be fundamental to the cause of achieving a more meaningful and fruitful educational experience. Thus, the discussion in this paper on White power and privilege is a key piece of the equation to grappling with educational policy development and the oversight of our schools.

\section{Aboriginal peoples}

Aboriginal peoples, often referred to as First Nations, are not a homogeneous group, and include a range of nomenclature: on-reserve, off-reserve, Métis, Inuit, dozens of bands and tribes, and various territorial and treaty-rights groups, which are spread throughout the country, and represent a number of linguistic and cultural perspectives. The relationship with Aboriginal peoples since the beginning of European contact is a history shrouded in exploitation and disregard for the indigenous population. In the early years of Confederation, the Indian Act ensured control over Aboriginals by prohibiting the potlatch ceremony (1884) and the sun dance (1885), and, in 1885, introduced a "pass system" prohibiting outsiders from entering reserves without permission from an Indian Affairs agent, and also restricting movement of Aboriginals off-reserve (Royal Commission on Aboriginal Peoples 1996). Despite the diverse regional conditions, there have been disputes, principally concerning treaty rights, characterized by road-blocks, protests, occupation of land, and even killings, across the country. The Royal Commission on Aboriginal Peoples (1996) concluded that: "Aboriginal people's living standards have improved in the past 50 years - but they do not come close to those of non-Aboriginal people", emphasizing the gap in life expectancy, education, housing, health care, access to water and sanitation, employment, and incarceration rates. More than a decade later, Mendleson (2006) confirms that Aboriginal peoples face a number of entrenched systemic barriers to accessing and achieving high educational outcomes as well in other areas of socio-economic concern (Canadian Council on Social Development, 2003). The disconnection between high academic standards and achievement for Canadians as a group, on the one hand, and the lived experience and formal and informal realities of First Nations, on the other, speaks directly to the need for a critical examination of the place of identity in education policymaking. The effect of 
Whiteness on the educational, cultural, political and economic development of Aboriginal peoples is indisputable (Lindberg, 2007).

\section{African-Canadians}

Little known for many Canadians is the fact that Blacks have formed an important part of the Canadian identity from the outset of the European founding of Canadaii . With the arrival of Samuel de Champlain in 1604 came Mathieu de Costa, a Black man from the Caribbean, who served as an interpreter with the Micmac peoples. Numerous Black communities arose in places like Chatham, Ontario, and Buxton, Halifax, and, perhaps somewhat surprisingly, in the mid-1800s Toronto had a significant black population ${ }^{\text {iii }}$. The existence of slavery in the Canadian ethos is often down-played or ignored despite it being a significant part of the nation-building process. Therefore, the history of AfricanCanadians is rich and deep, although under-documented and not celebrated, and speaks to a reality that is not fully understood or accepted by mainstream Canada, nor the decisionmaking elites. Longstanding issues of racial discrimination in education (Dei, Mazzuca, McIsaac \& Zine, 1997) and employment, segregation, over-representation in prison, marginalization from decision-making, and racial profiling (Smith, 2004) are a testament to the legacy of uncomfortable race relations in Canada (Fleras, 2002). The recognition of the Ontario Royal Commission on Learning (1995) that Black-focused schools should be considered, further, reveals the need to understand the racial variable within the educational context, and, importantly, also underscores the prevalence of Whiteness.

\section{Racial and ethnic diversity in Canada}

The formal Canadian identity includes a multitude of symbols, milestones, laws and cultural phenomena underscoring that, in terms of power, it is principally structured as a White country (Carr \& Lund, 2007). A number of important events and practices illustrate how, despite the pivotal role that they have played in constructing Canadian society, immigrants to Canada have faced a plethora of formal and informal obstacles ${ }^{\text {iv }}$. For instance, Canada has discriminated against the Chinese (1903 - Head tax), East Indians (1914 - refused admittance), socialists (1918 - declared illegal), the Doukhobors, Mennonites and Hutterites (1919 - prohibited entry), Jews (1939 - ship denied entry), Japanese-Canadians (1942 - internment), and other groups. Canada has a multicultural population but the most diverse sectors are centralized in its three largest cities--Toronto, Vancouver and Montreal--, which distinguish themselves from the rest of the country, owing to their extremely heterogeneous populace (Ornstein, 2000; Reitz \& Bannerji, forthcoming). Ornstein (2000) has provided ample evidence of higher rates of unemployment and poverty for certain racial minority groups compared to White, European-origin Torontonians, and the situation is most likely more pronounced outside the most diverse city in the country. Identity is complex, and, as it is socially constructed, it shifts and vacillates depending on the social context, becoming all the more relevant in ascertaining how power is distributed, and how pluralism manifests itself (Vincent, 2003). Thus, people of "colour," those who are non-White, based on that unique criterion, notwithstanding the social construction of identity, have been adversely affected by White power and privilege in society, in politics, in business, and in education. 


\section{Canadian ethos regarding racism}

To conclude this section on Canadian demography, it may be helpful to briefly underscore the national sentiment concerning racism. Canadians are, generally speaking, fond of deflecting complaints of racism by pointing to the less than enviable history and present-day reality in the United States (Carr \& Lund, 2007). In their study of racial inequality and social cohesion in Canada, Reitz and Banerjee (2006) found that visible minorities, especially Blacks, reported experiencing discrimination at 3-4 times the rate of White Canadians. Ironically, their study also revealed that "greater experience in Canada seems to lead to a larger racial gap in the perception of discrimination" (p. 11), which would appear to contradict the prevailing view that second- and third-generation visible minority immigrants integrate more seamlessly.

With the ample evidence of racial discrimination (prejudiced attitudes; human rights cases; field tests of discrimination; statistical analysis of earnings gaps), Reitz and Banerjee (2006) highlight studies illustrating how White Canadians, to a lesser degree than visible minorities, acknowledge that racism does, indeed, exist in Canada. Therefore, the different manifestations of anti-racism in Canada and the US are not necessarily cause for celebration as every context contains its own unique particularities, and underscore, rather, how racism is situational, shaped by historical forces, and subsumed in the torment of neo-liberalism.

\section{Whiteness in a colour-blind society}

Is it possible to speak of anti-racism, or social justice, without contextualizing Whiteness? Whiteness has to do with power and privilege, and is a fundamental construct to understanding how inequities are formed and perpetuated (Dei, Karumanchery \& Karumanchery-Luik, 2004). While emphasizing the social construction of identity, the lived experience of being White is considered pivotal to unblocking injustice (McIntosh, 1988). Women have long argued that men have been out of touch with their realities, and, therefore, a broad range of measures have been introduced attempting to rectify systemic, institutional and individual discrimination. However, at the programmatic and institutional levels, it has been mainly White, middle-class women who have benefited from these gains, not women of color. The Toronto Board of Education vigorously pursued a policy of affirmative action for women in the $1980 \mathrm{~s}$, with the result being that today a large percentage of the principals in elementary and secondary schools are women, predominantly of the White race (Carr, 1996).

Solomon, Portelli, Daniel and Campbell (2005) document how White teacher education candidates in Canada resist and downplay their own racial identities. Using an American lens, Marx and Pennington (2003) highlight the confounding relationship between being "good" and being "racist":

Thus, naming racism within themselves (White pre-service teachers) was at first cause for great concern. This is the point where guilt, fear, and even trauma came into the picture. Because they viewed goodness and racism as a dichotomy, their first glimpse of their racism led them to the conclusion that they must be horrible people. It seemed that, in coming to terms with their own racism, our 
students/participants necessarily had to make the connection that they could still be good be people and still be racist.... Moreover, despite their altruistic hearts and their efforts to "hide" their racism, it is still possible for their racism to hurt the children they teach (p.105).

Carr and Klassen (1997), in their study of the perceptions of race in education in the Toronto Board of Education, found that White and racial minority teachers had significant differences in how they viewed anti-racist education and discrimination in education. Their conclusions highlight the importance of lived experience and bone fide access to power as being key determinants in framing the educational institutional culture as it pertains to social justice.

Thompson, (2003) argues, as do Dei, Karumanchery, and Karumanchery-Luik (2004) within the Canadian context, that Whiteness must be challenged for there to be meaningful change in education:

this (decentering Whiteness) means relinquishing our cherished notions of morality: how we understand fairness, how we understand what it means to be a good person, how we understand what it means to be generous or sympathetic or tolerant or a good listener. When we are challenged for our whiteness, our tendency is to fall back on our goodness, fairness, intelligence, rationality, sensitivity, and democratic inclusiveness, all of which are caught up with our whiteness (pp. 16-17).

As co-editor, with Darren Lund, of The great white north? Exploring whiteness, privilege and identity in education (2007), we pose several questions "that seem selfevident and yet confound our work":

Do most White people even know that they are White? Do they use their own privilege to deny or ignore their racial identity and, simultaneously, infer inherent racial attributes to the "Other? If White people do not know they are White, how can those in positions of power, many of whom are White, effectively understand and challenge racism and unearned privilege? (p. 2)

We frame the notion of Whiteness, as illustrated by Reitz and Banerjee (2006), around the particular Canadian context in which the general sentiment is that the United States is more of a historically racist society than is Canada. Yet, Canada has been home to a litany of racist events, actions, policies and legislation. Solomon and Daniel (2007) further flesh out the problematic of White privilege in documenting how little Canadians generally know about racism in Canada, and also emphasize the importance of meaningful, critical and engaged education as a means to bringing about social justice in the classroom. Therefore, to develop educational policy, it is imperative to acknowledge, understand, critically diagnose and re-align structures and processes to take into account crucial variables, such as lived experience, the social construction of identity, the distribution and exercise of power, the political nature of society, and, importantly, the conceptualization and manifestation of social justice.

\section{Defining anti-racism in Canada}

Anti-racist, or anti-racism, education, as a philosophy, a concept, and an approach, started to take shape in Canada, borrowing from the British example, in the early 1980s (Dei, 1996; Carr \& Klassen, 1997). As it evolved, anti-racism was deemed a more critical and 
political response to diversity and equity in Canada than the well-entrenched multiculturalism that had permeated the mainstream of society (Dei, 1996). One of the first practical guides in Canada to espouse an anti-racism pedagogical approach is Enid Lee's Letters to Marcia (1985), which echoed the prevailing sentiment of the day that "Raising the topic (of racism) might be compared to breaching a code of conduct. Some of us believe that the more we talk about racism the worse it becomes" (p.6).

Whereas multiculturalism was traditionally perceived to support the "social contact" theory (getting diverse people to interact with one another), tolerance, openness, and exposure to different cultures, traditions and origins, anti-racism was conceptualized to address systemic, structural inequities, and, importantly, to focus on power relations, with a particular interest in racism. To this end, issues of differential outcomes for various groups (for example, African-Canadians and First Nations), the underrepresentation of some groups in the teaching and administrative fields, and a Eurocentric curriculum, all become pivotal concerns. However, it is important to point out that critical approaches to multicultural education have overlapped with the primary tenets of anti-racism in many regards, and the strict definitions once used are no longer applicable (see, for example, Joshee \& Johnson, 2007, and Banks, 2008). Ghosh (2001) and Fleras (2002) have provided comprehensive texts on multiculturalism that summarize the range of issues that have often been packaged under the rubric of diversity, and which also mesh with anti-racism, although the tone may be less sharp than those advocating a more obvious critical pedagogical approach (Kincheloe, 2008; McLaren, 2007).

One of the most prominent anti-racism theorists in Canada over the past fifteen years has been George Dei, who teaches at the Ontario Institute for Studies in Education at the University of Toronto. The fundamental premises of Dei's conceptualism of antiracism education (see Carr \& Klassen, 1997, p.49) concern the social effect of "race", the intersectionality of various forms of social oppression, the salience of White (male) power and privilege, recognizing that students are not "disembodied" individuals but that their background and identities are implicated in the schooling and learning processes, acknowledging the pedagogic need to confront diversity and difference, and questioning explanations of pathological family and home environments as a source of school problems.

The construction of anti-racism is not devoid of criticism, as Pon (2000) highlights the need to "(Conceive of) power... to (understand) present-day race and racism in Canada and the United States and (get) beyond the paradigms of Black/White race relations and majority/minority cultures" (p. 149). Similarly, in advocating a broader and more fluid conceptualization of identity, he argues for a more nuanced interpretation of the manifestation and exercise of power, something at the core of the conceptualization of anti-racism education. Similarly, Yon (1999) is concerned about the tendency to privilege notions of difference between groups as a means of structuring debate and reality, which can serve to undermine action related to inequitable power relations. As a response to concerns about the weakness of anti-racism to address social justice, Dei (2007) has promoted a vision of integrative anti-racism, which incorporates the intersectionality of identity, and also emphasizes the salience of White power and privilege.

In sum, the multiculturalism/anti-racism debate, thus, provides a context for understanding racism in society, and also serves as a useful starting-point for diagnosing, 
critiquing and taking action to improve the education system, especially with a view to addressing the key concern of social justice. One of the main tenets of anti-racism is to allow individuals and groups the space and voice to articulate who they are as well as being cognizant of the power and privilege to name the "other" (Dei, 1996). Being involved in the decision-making process to determine racial, linguistic, ethnic and cultural categories is, therefore, integral to public policy development (Carr, 1999). Avoiding recognizing difference can only compound pervasive systemic barriers (James, 2003).

\section{Analyzing anti-racism programs in education}

When looking for tangible, comprehensive policies dealing with anti-racist education in Canada, one is struck at how little, concrete direction there actually is. There are usually preambles in policy documents inferring a commitment to equity but the actual funding, processes, staffing, content and, significantly, accountability, are not predominantly featured, nor are they transparently visible (Carr, 1999; James, 2003). To underscore this point, the whole area of social justice is not generally placed on a similar plain as the multitude of areas that are formally tested, and for which generous resources are provided to develop, implement and assess curriculum, achievement and institutional standards (Carr, 2007b; McLaren, 2007). Are educational systems in Canada preoccupied with ensuring that students receive a holistic, inclusive, anti-discriminatory education immersed in social justice, as exemplified by how and what they learn as well as the activities that characterize their educational experience inside and outside of the classroom (Westheimer \& Kahne, 2004)? How does the neoliberal policy agenda account for social justice? Can the Canadian education system strive for high academic achievement and also aim for broad accessibility and critical learning (equity) concurrently (Leithwood \& Riechl, 2003)? Ultimately, anti-racism involves a political engagement that surpasses symbolic measures.

\section{The Ontario Case in the 1990s}

An example of the equity waltz, to extend the analogy employed in the title, is the rather rapid, tumultuous shifting of climate and context in Ontario in the mid-1990s. Progressively, for a number of years, the Toronto Board of Education (TBE) developed a staff complement, research base, policy framework and institutional culture favorable to the equity agenda (Carr, 1999; Carr \& Klassen, 1997). The TBE had a multitude of mandated committees, initiatives, research projects and public displays of formal and informal support. While the TBE was open to criticism, other jurisdictions often were reluctant to consider discussion of the matter. McCaskell (2005), a student program worker in the Board's Equal Opportunity Office, has reported on the inner turmoil and struggles related to advancing social justice in the Board, and concludes that the challenges were monumental but that some important, far-reaching equity work was being accomplished. Some of this innovative work by the TBE included multicultural/multiracial residential camps for secondary school students (McCaskell, 2005), and the collection, analysis and dissemination of data on achievement and 
educational experience of students based on identity (for example, Brown, 1999), which was virtually unheard of in Canada throughout the 1980s and 1990s.

As the Toronto Board distinguished itself as a leader both nationally and internationally with its vigorous equity programs, which included race relations, gender equity, working-class issues, curriculum development, community outreach, research and other institutional measures, the Ontario government, for the 1990-1995 period, for the first time in history, was led by a left-leaning, more openly social justice-based New Democratic Party (Carr, 1999, 2007b). One of the pillars of the government's policy agenda was anti-racism, and a plethora of policies, programs and structures were put in place, all with the requisite funding. This translated into Assistant Deputy Minister and Director positions for Anti-racism and Ethno-cultural Equity in the Ministry of Education, both filled by former TBE employees, and a government-wide Ontario Antiracism Secretariat, which was placed under the leadership of another former employer of the TBE (Carr, 2007b).

Along with the training, communications, and overall shift in institutional culture, however contested, the Ontario Ministry of Education produced an anti-racism and ethnocultural equity policy for school boards, which mandated boards to plan for and implement strategies to address important social justice concerns, including the curriculum, training, leadership, staff development, evaluation, harassment, and schoolcommunity partnerships (Ontario Ministry of Education, 1993). This policy went farther than previous articulations of the problem within the Canadian context in relation to the existence of racism, stating boldly that it is "based on the recognition that some existing policies, procedures, and practices in the school system are racist in their impact, if not their intent, and that they limit the opportunity of students and staff belonging to" (Ontario Ministry of Education, 1993,p. 5). The policy can be considered avant-gardiste in a number of ways: 1) it presented a plan of action; 2) it emphasized social justice, which some considered to conflict with high academic standards; 3) it contained provisions for accountability; 4) it aimed to address systemic barriers in addition to individual attitudes; and 5) it sought to bring into the decision-making fold marginalized groups, which was rejected by those claiming that "merit" should be the only criterion for participation in educational policymaking (Carr, 2007b).

The government produced an impressive range of committees, reports and initiatives, particularly the discussion-document Changing Perspectives (Ontario Ministry of Education, 1992), which invited an open dialogue on the issue of race and ethnicity in education. Subtitled A Resource Guide for Antiracist and EthnoculturalEquity Education, it laid the groundwork for discussing a more activist, inclusive role for education, and also articulated a clear vision of antiracism, which "will enable all students to" "feel that their culture and identity are affirmed by the educational system" and also "accept and appreciate diversity and reject prejudiced and discriminatory attitudes and behaviour" (Ontario Ministry of Education, 1992, p. 3). The document also clarified that "Antiracist education calls for educators to recognize how discrimination, distortions, and omissions occur; to correct distortions and remedy omission and discriminatory conditions; and to establish practices and procedures consistent with the goals of equity education" (Ontario Ministry of Education, 1992, p. 2). Therefore, with the formal recognition of a Euro-centric, White bias in education, educators were 
encouraged, and in a policy sense, required, to adhere to Ministry of Education guidelines aimed at inculcating equity in education.

The trickle-down effect throughout the educational system in Ontario, to school boards, schools, and educational associations, including administrators, teachers and other stakeholders, stemming from the formal articulation of a social justice focus, was as impressive as it was expeditious (Fielding, 2002). Not all those involved were as equally engaged, nor did they seek the same level of change but the focus was considered to be favorable to the equity-seeking public (Corson, 2001). The education-system was required to follow suit in order to continue receiving funding, and, at a strategic level, to have access to decision makers. One example of this was the resource-guide produced by the Ontario Secondary School Teachers Federation (Coelho, Costiniuk and Newton, 1995), entitled Antiracism Education: Getting Started, A Practical Guide for Educators. This is a visible testament to the power of government to control the language of public discourse, acknowledging anti-racism instead of multiculturalism or some other nomenclature, and also to push stakeholders into a more equity-positive mind-set.

On June 8, 1995, the Progressive Conservatives, under the leadership of Mike Harris, won the provincial election, and, within days, formally dismantled years of equity work. The employment equity legislation, which was labeled incompatible with the "merit principle" (Klassen \& Cosgrove, 2002), was immediately abolished, the Ontario Anti-racism Secretariat soon followed, the Ministry of Education's Anti-racism and Ethno-cultural Equity Branch was phased out, and funding for all of the previous activities was cut off (see Corson, 2002). The anti-racism policy in education (Ontario Ministry of Education, 1993), while not formally revoked, was never implemented or monitored, despite there being a requirement for boards to submit annual progress reports, with which none instinctively complied. The Conservative government also put an end to several well-developed curriculum initiatives, including an Aboriginal antiracism education document, an anti-racism teacher's resource-document, and a guideline for principals to detect and deal with hate crimes in schools (see Carr, 2007b). The new business plans under the Conservatives did not contain any equity provisions, and this meant that work from the inside would become exceedingly difficult. A direct consequence is that boards and stakeholders that did fashion a progressive take on equity, such as the TBE, slowly down-sized operations, unable to counter the will and direction of the chief funder and decision-maker at the provincial level (McCaskell, 2005).

At the curricular level, the Harris government re-wrote the entire curriculum, emphasizing high standards and a decidedly business flavor, effectively removing any significant reference to equity and anti-racism (Fielding, 2002). Black (2003), in his review of anti-racism in education in Ontario, found that "The word "racism" cannot be found within the curriculum for any compulsory course", "Racism' appears in only two of 22 ministry-approved Canadian history textbooks published prior to 2000", and "Courses and workshops in anti-racist teaching methods are elective, so only those teachers already interested receive advanced instruction on the topic" (p.1).

The Conservative government's framework policy document overseeing the reform at the secondary level, Ontario Secondary Schools, Grades 9 to 12, Program and Diploma Requirements (Ontario Ministry of Education, 1999), offered a detailed and prescriptive overview of all of the major aspects for the teaching and learning of students. Significantly, all of the principle touchstones of neo-liberalism are highlighted (i.e., "high 
standards", "accountability", "expectations", "education and work", "independent, productive, and responsible members of society", "measurable results" and parental responsibility), framing the importance of creating a competitive workforce ("employability") for the "twenty-first century". The 82-page policy document consecrates only one page for "antidiscrimination education", which is sufficiently vague and non-prescriptive, avoiding accountability, in that it does not carry any proportionate weight in comparison to other tangible requirements such as the Individual Education Plan (IEO), the Teacher-Advisor program, and the Annual Education Plan. It highlights, for example, "equal opportunity", and "asks", not "requires," that "Students entering the system should be given the support they need to adjust to the new environment", and "Teachers, including guidance counselors and teacher-advisors, should give support to students that is appropriate to their strengths, needs, and backgrounds so that all students have a chance to succeed" (p.59).

What is most striking here is that the previous anti-racism educational policy is not mentioned, nor is there any bone fide accountability mechanisms identified to ensure that students will receive an education appropriate for their needs (Carr, 2006). Additionally, there is no mention of financial and human resources to ensure the full articulation and implementation of antidiscrimination education. The language used emphasizes diversity without there being any focus on systemic barriers, inequities and marginalization.

\section{Other manifestations of anti-racism in Canada}

The policy response of provincial governments in Canada in relation to equity is mixed, in that formal pronouncements are often followed by minimalist, nuanced programs and missed opportunities. When examining formal enunciations of diversity-related responses in Ministries of Education across the country, there is little that expressly addresses the intent of the Ontario policies of the early 1990s. In some cases, policies attempt to mollify equity-seeking groups by including vague and indirect provisions within citizenship education or similar educational themes ${ }^{\mathrm{v}}$.

One example of the softer, more indirect trend, in relation to equity in education, is the 40-hour voluntary service requirement in Ontario, which is, ironically, a "mandatory" graduation requirement (Ontario Ministry of Education, 2000). This policy has no structured and progressive framework, in that no funds are provided by the government to ensure that students have a meaningful community-service experience, and, further, schools are not required to inter-weave this potentially invaluable component with their formal educational program. One might ask if 40 hours over a fouryear period is sufficient to actually do community work, especially since it may take that amount of time to be trained to undertake a particular task. Westheimer and Kahne (2004) have questioned the utility of community-service work without some direct political connection, and this is significantly lacking from the Ontario policy. Students should be made aware of the reasons for poverty, for example, and not just that a food bank serves food to people who are hungry, as this may reinforce the notion that somehow poor people are the authors of their own destiny; further, by donating a can of food, it is important to understand that the problem of poverty still exists. Similarly, do students engage in anti-racism activities, grounded in the educational experience, that are 
sustained, critical, action-based and relevant or might they considered contrived, superficial and inauthentic?

A significant thread to the policy development conundrum pertains to the radically fluctuating international pressures, from which educational policymaking must develop appropriate responses for local, territorial and national educational systems. Lund (2006) has researched anti-racism social activism and policies in Canada, especially in Alberta, and concludes that, despite the booming economic prosperity in Canada's richest province, the neo-liberal strangle-hold on education has had a significant impact on the educational experience of students: "So even though some government, community, and other organizations addressing diversity still exist in Alberta, many of them have faced restructuring and downsizing in recent years.... this lack of political will to address racism and other discrimination through policy and programming negatively influences the work they (teachers and students) do in this field (p.36).

In another study, Lund and Fidyk (2006) examined the availability and usage of anti-racism education resources in Canada, stressing that a "climate of constraint and additional demands for those (anti-racist) educators dedicated to these types of programs in schools" are barriers to implementing social justice measures (p.60). A key consideration, however, relates to being able to support the usage of social justice materials through training, professional development, integration into and throughout the curriculum, and the establishment of an institutional culture conducive to addressing systemic issues related to (in)equity. Ultimately, the formal curriculum alone cannot transform the educational system, nor the experience of students; the informal, or hidden, curriculum must also be a major component in rectifying inequity and marginalization (Apple, 1996).

\section{Considerations and perspectives for policy development and research}

How do we know if we are making progress on the equity file (Leithwood \& Riehl, 2003)? One visible way is to determine what data are collected on equity, how issues are defined, if there are standards and benchmarks indicating how we achieve equity, whether there is funding, staffing and resources especially dedicated to equity, and, finally, if there is a visible presence and dialogue on the subject. In other words, outcomes are important when thinking about social justice. What do Ministry of Education and national reports, such as the Pan-Canadian Indicators Program, say about equity? How does the formal structure for assessing achievement reconcile the indisputable need for equity (Kim \& Sunderman, 2005)? Do educational-systems have frameworks in place to effectively cultivate a social justice experience? Importantly, is there room for social justice in education within a time of a neo-liberal focus on competition, high standards, enhanced practical and business knowledge, and standardized testing (Lauder, Brown, Dillabough, \& Halsey, 2006)? Also of critical importance is how the educational policy process and institutional culture take into consideration the decision-making process with marginalized groups, including those discussed in the earlier sections of the paper.

Carr (2007a), in his analysis of how educational policy is developed, based, in part, on his experience working in the Ontario Ministry of Education (Carr, 2006), highlights 
five key considerations as to how the educational institutional culture responds to social justice concerns:

- resisting change and rupturing progressive work (how easily the equity agenda can be splintered, de-railed and marginalized by competing interests and uncooperative institutional and leadership elements);

- shaping the policy message (the gulf between an idea and how that idea will be realized and implemented, characterized by a lack of knowledge, commitment, research-base and diverse people involved in the formulation of the problem);

- controlling the agenda (the operational apparatus scaffolding the equity agenda can serve as an unnecessary deterrent to proceeding with tangible action, mired in institutional intransigence and layers of decision-making that are usually foreign to equity-seeking groups);

- developing curriculum and educational policy (the tussle over the formal policy terrain involves endless compromises and political trade-offs, and can become disjointed, owing to non-integrated strategies);

- White complicity and privilege (involves a reluctance to acknowledge inequity and personal and collective implication based on racial group affiliation, and also relates to preserving inequitable power imbalances).

The question of accountability in education in relation to social justice is, therefore, pivotal to understanding the degree to which society, governments and decision-makers value progressive change. Accountability within the neo-liberal context has often focused on standards, which avoid addressing social justice or concrete spending and administrative milestones that are oblivious to the notion of inclusivity, power-sharing, democratic learning and the contextual reality for marginalized groups (McLaren, 2007; Kim \& Sunderman, 2005). The Ontario example highlighted in this paper underscores the superfluous commitment to accountability when it comes to antiracism education.

In the US context, there is evidence that the "accountability requirements of the No Child Left Behind Act of 2001 place high-poverty schools and racially diverse schools at a disadvantage because they rely on mean proficiency scores and require all subgroups to meet the same goals for accountability" (Kim and Sunderman, 2005, p. 3). Further, Hoover and Shook (2003) question the relevance of teaching and learning within the era of strident accountability, highlighting that "the threat to teaching, experiencing, and realizing democratic ideals (which) has never been more real, especially as teaching convention is driven almost entirely by invalid proficiency tests and pseudoaccountability mechanisms" (p.8). Therefore, accountability is a societal issue, involving all sectors, and requiring institutional engagement. Democratic leadership and a renewed commitment to social justice by educational administrators (Leithwood and Riehl, 2003) is a critical element in restoring credibility to, and for, the educational system. This leadership should be cognizant and conversant with the notion and impact of Whiteness.

Elsewhere (Carr, 2007b), I have a proposed a Social Justice Accountability Framework (Figure 1), in which content variables and functional criteria are assembled in a matrix to form an organizational and operational model to facilitate institutional transformation in education. The principle is simply that specific educational sites-for example, at the school board or provincial/state levels-would consecrate the required human and financial resources in order to elevate social justice concerns to that identified 
by neo-liberal reforms, which commonly underplay and marginalize them. Ultimately, the notion of accountability requires authentic leadership, one that takes into consideration identity and lived experience (Leithwood and Riehl, 2003). There is the concern that social justice efforts will be co-opted in an effort to legitimate the status quo; however, the proposed model (Carr, 2007b) aims to frame and obligate institutions to embark on a planning, development, and implementation process that requires accountability for a range of fundamental social justice concerns that have traditionally been neglected. At the operational level, each content variable on the left side of the Accountability Framework is to be analyzed and debated in light of the various functional criteria on the top of the matrix, ultimately culminating in the drafting of objectives and standards, with the concomitant resources and leadership being allocated to ensure a bona fide social justice presence and, importantly, outcome.

Figure 1: Social Justice Accountability Framework

\begin{tabular}{|c|c|c|c|c|c|c|c|c|}
\hline & 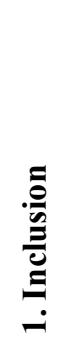 & 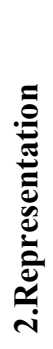 & 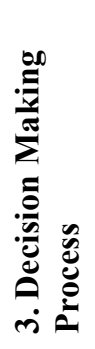 & 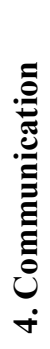 & 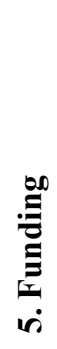 & 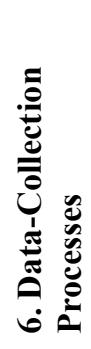 & 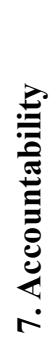 & 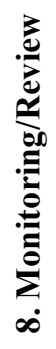 \\
\hline 1. Strategic $P$ & & & & & & & & \\
\hline 2. Leadership & & & & & & & & \\
\hline 3. Curriculun & & & & & & & & \\
\hline 4. Extra-Curr & & & & & & & & \\
\hline 5. Service-Lea & & & & & & & & \\
\hline $\begin{array}{l}\text { 6. Communit } \\
\text { Involvement }\end{array}$ & & & & & & & & \\
\hline 7. Training & & & & & & & & \\
\hline 8. Evaluation & & & & & & & & \\
\hline
\end{tabular}

For instance, for the Curriculum component, some of the guiding questions to be addressed would be: How does the curriculum (Social Studies and all other courses) effectively address social justice? How is Civics dealt with? What quality assurance mechanisms are in place to ensure the most effective teaching and learning of the curriculum? The Curriculum variable would then be reviewed according to the functional criteria, in which the following questions would be presented: 1. Inclusion (What processes, guidelines and strategies are employed to ensure that there are no barriers, systemic or otherwise, excluding groups and/or individuals, and what is the result? How is inclusion defined and understood by diverse stakeholders, and how do educational institutions continually strive to align their interests with the broader community?); 2. Representation (Who is represented in various spheres of leadership, policy development, program delivery, teaching, training, consultation, etc. in relation to gender, ethno-cultural origin, race, social class, and other identifiers, and what is the 
result?); 3. Decision-making Process (How are decision-making processes structured and implemented, and what is the result? What rights to appeal and review exist for decisions, and are there legal/budgetary/policy limits placed on decision-making processes?); 4. Communications (How are communications planned and delivered, and what is the result? How does the system ensure the effectiveness of communications? Is there a bone fide link between what is publicly said, and what actually takes place?);

5. Funding (What, and how, is funding provided? Are "value for money" and "costbenefit" analyses undertaken to ensure the effective use of funding? Is funding provided directly and indirectly for social justice activities?); 6. Data-collection and Analysis (What, and how, are data collected? How are the data analyzed, and what is the utility of this analysis? How are social justice implications considered regarding the collection of data?); 7. Accountability Mechanism (What mechanisms are explicitly in place to ensure fairness, effectiveness, and accountability? Are students, teachers, administrators, Department of Education and others permitted and encouraged to question accountability processes and results?); 8. Monitoring and Review (What are the policies and processes in place to ensure over-sight and follow-up? How are diverse constituencies involved in monitoring and reviewing of social justice?) (Carr, 2007b).

The objective here is to specifically focus on social justice, of which anti-racism is a predominant feature, as opposed to the broader neo-liberal themes of financial accountability and academic outcomes that do not consider marginalization, identity and inequitable power relations. The people involved in this social justice accountability process as well as the questions raised distinguishes it from traditional strategic planning exercises, which avoid stipulating how meaningful social justice area will be achieved. Therefore, accountability for social justice in education within a time of pervasive neoliberalism requires a comprehensive, systemic and institution-wide approach that fully interrogates identity and power relations at the base.

In the neoliberal era, the shift from, arguably, a more citizenship-based mission for public education to an extremely sophisticated and nuanced quest for employmentfocused outcomes has filtered down throughout the education system. Without fully addressing the systemic barriers that prevent society from redistributing wealth and opportunity, public education has been widely considered as an important vehicle to facilitate some mobility between social classes (Dewey, 1916; Freire, 1973; Banks, 2008). A focus of this paper has been on the frittering away of some of the equity and social justice gains that have been made, while also recognizing that there is significant need, and potential, to accomplish these worthy aims for public education. It is telling that such gains, as exemplified by the equity waltz, can be so quickly dismantled.

Ultimately, to suggest that equity, social justice and anti-racism are integral features to the educational experience, it would be necessary to establish formal standards, outcomes and policies, thus legitimating their place, and also ensuring that the myriad actors in the teaching and learning process are attuned to the diverse priorities in education, outside of the avalanche of prescriptive testing and curriculum milestones. The social context is, undoubtedly, a fundamental factor in understanding why some students do not achieve as well as others (McLaren, 2007). More integrated and critical engagement around equity could help improve outcomes for all students, thereby providing a veritable learning experience that extends well beyond questionable standardized tests (Westheimer \& Kahne, 2004). Recognizing and validating identity--as 
illustrated earlier in this paper (James, 2003)--and power structures are a key component to legitimizing the social justice agenda.

In sum, implementing anti-racism education is not a luxury or add-on activity to be drawn on in times of trouble; it should be an organizing principle, around which substantive and broad teaching and learning experiences are mobilized. In a multicultural society characterized by hope, vigor and dynamism, there are untold benefits to proceeding with sustained, integrated leadership, accountability measures and classroom learning, whereas the damage created by avoiding the inevitable is as equally farreaching $^{\text {vi }}$. Finally, critically interrogating the meaning and salience of Whiteness throughout the policy development, accountability and educational experience should be a necessary step to engaging debate and action around anti-racism and social justice. Otherwise, there is a serious potential to be locked in an equity waltz, in which tangible, meaningful social justice gains are always at risk of being overturned.

\section{References}

Apple, M. (1996). The hidden curriculum and the nature of conflict. In Parker, W. (Ed.), Educating the democratic mind (pp.173-199). Albany, N.Y.: State University of New York Press.

Banks, James. (2008). An introduction to multicultural education. Boston: Allyn and Bacon.

Banks, J. et al. (2005). Democracy and diversity: Principles and concepts for educating citizens in a global age. Seattle: Center for Multicultural Education Publications.

Banks, J. et al. (2005). Democracy and diversity: Principles and concepts for educating citizens in a global age. Seattle: Center for Multicultural Education Publications.

Black, K. (2003). Erasing anti-racism: A decade later, anti-racism education is still nonexistent in the classroom, NOW Magazine, 23(7). Retrieved September 3, 2006, from http://www.nowtoronto.com/issues/2003-10-16/news story4.php .

Brown, R. (1999). A study of the grade 9 cohort of 1993, 1993-1998: The last grade 9 cohort of the Toronto Board of Education. Toronto: Toronto District School Board.

Canadian Council on Social Development. (2003). Aboriginal children in poverty in urban communities: Social exclusion and the growing racialization of poverty in Canada. Ottawa: Canadian Council on Social Development.

Carr, P.R. (1996). Anti-racist education, institutional culture and the search for Educational Transformation. Unpublished doctoral thesis at the Ontario Institute for Studies in Education at the University of Toronto.

Carr, P.R. (1999). Transforming the institution, or institutionalizing the transformation? Racial diversity and anti-racism in education in Toronto, McGill Journal of Education, 34 (1):49-77.

Carr, P.R. (2006). Social justice and Whiteness in education: Color-blind policymaking and racism, Journal for Critical Education Policy Studies, 4, 2. Retrieved February 3, 2007 from: http://www.jceps.com/index.php?pageID=article\&articleID $=77$

Carr, P.R. (2007a). Educational policy and the social justice dilemma. In Claire, H. and Holden, C. (Eds), Controversial Issues in Education (pp.1-10). London: 
Trentham.

Carr, P.R. (2007b). Standards, accountability and democracy: Addressing inequities through a social justice accountability framework, Democracy and Education, $17(1)$.

Carr, P. \& Lund, D. (in press). Antiracist Education. In Provenzo, E. (Ed.), SAGE Encyclopaedia of Cultural and Social Foundations of Education. Thousand Oaks, California: SAGE Publications.

Carr, P.R. \& Lund, D.E. (Eds.). (2007). The great white north? Exploring whiteness, privilege and identity in education. Rotterdam: Sense Publishers.

Carr, P. \& Klassen, T. (1997). Different perceptions of race in education: racial minority and White teachers. Canadian Journal of Education, 22(1), 67-81.

Carr, P. \& Klassen, T. (1997). Institutional barriers to the implementation of anti-racist education: A case study of the secondary system in a large, racially diverse, urban school board, Canadian Journal of Educational Administration and Foundations, 12(1),46-68.

Coelho, E., Costiniuk, B. \& Newton, C. (1995). Antiracism education: Getting started a practical guide for educators. Toronto: Ontario Secondary School Teachers Federation.

Corson, D. (2001). Ontario students as a means to the government's end, Our Schools Our Selves, 10(4), 57-80.

Dei, G. (1996). Antiracism education: Theory and practice. Halifax: Fernwood Publishing.

Dei, G. (2007). Foreword. In Carr, P. \& Lund, D. (Eds), The great white north: Exploring whiteness, privilege and identity in education (pp. vii-xii). Rotterdam: Sense Publishers.

Dei, G., Mazzuca, J., McIsaac, E. \& Zine, J. (1997). Reconstructing 'drop-out': A critical ethnography of the dynamics of Black students' disengagement from school. Toronto: University of Toronto Press.

Dei, G., Karumanchery, L. \& Karumanchery-Luik, N. (2004). Playing the race card: Exposing white power and Privilege. New York: Peter Lang.

Dewey, J. (1916). Democracy and education. New York: MacMillan.

Fielding, K. (2002). Tales from the crypt or writing the Ontario Canadian and World Studies curriculum. Our Schools Our Selves, March. Retrieved August 25, 2006, from

http://www.policyalternatives.ca/index.cfm?act $=$ news \&call $=789 \&$ do $=$ article $\& p A$ $=\mathrm{BB} 736455$

Fleras, A. (2002). Engaging diversity: Multiculturalism in Canada. Toronto: Nelson Thomson Learning.

Freire, P. (1973). Pedagogy of the Oppressed. New York: Continuum.

Ghosh, R. (2001). Redefining multicultural education. Toronto, Ontario: Nelson Thomas Learning.

Hill, D. (2003). Global neo-liberalism, the deformation of education and resistance, Journal for Critical Education Policy Studies, 1,1. www.jceps.com/?pageID=article\&articleID=7.

Hoover, R. and Shook, K. (2003) School reform and accountability: Some implications and issues for democracy and fair play, Democracy and Education, 14(4), 81-86. 
James, C. E. (2003). Seeing ourselves: Exploring race, ethnicity and culture. Toronto: Thompson Educational Publishing, Inc.

Joshee, R. \& Johnson, L. (2007). Multicultural education policies in Canada and the United States. Vancouver: UBC Press.

Lauder, H., Brown, P., Dillabough, J. \& Halsey, A.H. (2006). Education, globalization and social change. London: Oxford University Press.

Lee, E. (1985). Letters to Marcia: a teacher's guide to anti-racist education. Toronto: Cross Cultural Communication Centre.

Leithwood, K. \& Riehl, C. (2003). What we know about successful school leadership. Philadelphia: Laboratory for Student Success, Temple University.

Lindberg, T. (2007). On Indigenous academia: The hermeneutics if Indigenous Western institutional participation-Eleven theorems. In Carr, P. \& Lund, D. (Eds). The great white north? Exploring whiteness, privilege and identity in education (pp. 67-75). Rotterdam: Sense Publishers.

Lund, D. (2006) Waking up the neighbors: Surveying multicultural and antiracist education in Canada, the United Kingdom, and the United States, Multicultural Perspectives, 8(1), 35-41.

Lund, D.E., \& Fidyk, A. (2006). Desperately seeking anti-racism education resources [feature article]. Directions: Research and Policy on Eliminating Racism, 3(1), 53-64.

Kincheloe, J. (2008). Critical pedagogy: A primer. New York: Peter Lang.

Kim, J. \& Sunderman, G. (2005). Measuring academic proficiency under the No Child Left Behind Act: Implications for educational equity. Educational Researcher, 34(8), 3-13.

Klassen, T. \& Cosgrave, J. (2002). Ideology and inequality: Newspaper coverage of the employment equity legislation in Canada (Working Paper Series, \# 28). Toronto: Centre for Research on Work and Society at York University.

Marx, S. \& Pennington, J. (2003). Pedagogies of critical race theory: Experimentations with white pre-service teachers, Qualitative Studies in Education, 16(1), 91-110.

McCaskell, T. (2005) Race to equity: Disrupting education inequality. Toronto: Between the Lines.

McIntosh, P. (1988). White privilege: Unpacking the invisible knapsack. Retrieved August 28, 2006, from http://www.case.edu/president/aaction/UnpackingTheKnapsack.pdf\#search=\% $\% 22$ peggy $\% 20$ mcintosh $\% 20$ independent $\% 20$ school $\% 22$.

McLaren, P. (2007). Life in schools: An introduction to critical pedagogy in the foundations of education. New York: Longman.

Mendelson, M. (2006). Aboriginal peoples and postsecondary education in Canada. Ottawa: The Caledon Institute of Social Policy.

Ontario Ministry of Education (1992). Changing perspectives. Toronto: Ontario Ministry of Education and Training.

Ontario Ministry of Education (1993) Antiracism and ethnocultural equity in school boards. Toronto: Ontario Ministry of Education and Training. Retrieved September 7, 2006, from http://www.edu.gov.on.ca/extra/eng/ppm/119.html . 
Ontario Ministry of Education (1999). Ontario secondary schools, grades 9 to 12: Program and diploma requirements. Toronto: Ontario Ministry of Education. Retrieved September 7, 2006, from http://www.edu.gov.on.ca/eng/document/curricul/secondary/oss/oss.pdf .

Ontario Ministry of Education (2000). Ontario secondary school diploma requirement: Community involvement activities in English-Language schools (Policy/Program Memorandum 124a). Toronto: Ontario Ministry of Education. Retrieved September 7, 2006, from http://www.edu.gov.on.ca/extra/eng/ppm/124a.html .

Ornstein, M. (2000). Ethno-racial inequality in Toronto: Analysis of the 1996 census. Toronto: City of Toronto. Retrieved September 2, 2006, from http://www.toronto.ca/diversity/reports.htm .

Pon, G. (2000). The art of war or the wedding banquet? Asian-Canadians, masculinity, and antiracism education, Canadian Journal of Education, 25(2), 139-151.

Reitz, J. \& Banerjee, R. (forthcoming) Racial inequality, social cohesion, and policy issues in Canada. In Courchene, T., Banting, K. and Wuttunee, W. (eds), Belonging? Diversity, recognition and shared citizenship in Canada. Montreal: Institute for Research on Public Policy.

Royal Commission on Aboriginal Peoples (1996). Report of the royal commission on Aboriginal peoples. Ottawa. Department of Indian and Northern Affairs, Canada.

Solomon, R.P. \& Daniel, B.J. (2007). Discourses on race and 'White privilege' in the next generation of teachers. In Carr, P. \& Lund, D. (Eds). The Great White North? Exploring

Whiteness, privilege and identity in education (pp. 161-172). Rotterdam: Sense Publishers.

Solomon, R.P., Portelli, J.P., Daniel, B.J., \& Campbell, A. (2005). The discourse of denial: How white teacher candidates construct race, racism and "white privilege". Race Ethnicity and Education, 8(2), 147-169.

Thompson, A. (2003). Tiffany, friend of people of color: White investments in antiracism, Qualitative Studies in Education, 16(1), 7-29.

Vincent, C. (2003). Social justice, education and identity. New York: RoutledgeFalmer.

Westheimer, J. \& Kahne, J. (2004). What kind of citizen? The politics of educating for democracy, American Educational Research Journal, 41(2), 237-269.

Yon, D.A. (1999). Pedagogy and the 'problem' of difference: On reading 'community' in The Darker side of Black, Qualitative Studies in Education, 12, 623-641.

\footnotetext{
Notes

${ }^{i}$ The Human Development Index and other international comparisons using social, educational, economic and political indicators consistently rank Canada within the best countries in which to live. Canada has even been awarded the top honours a few times in the past fifteen years.

ii A comprehensive resource documenting Black-Canadian history, produced by Historica Black History Canada, can be found at http://blackhistorycanada.ca/ .

iii The City of Toronto's Black history website at www.toronto.ca/blackhistory/victorian-exhibit.htm notes that approximately 1,200 of Toronto's 45,000 residents in 1860 were Black, and also that there was a vibrant Black business community there at that time.

${ }^{\text {iv }}$ A detailed summary of Canada's immigration history can be found on the No one is illegal website at http://noii-van.resist.ca/immigration history.html .

v This analysis is based on a review of the websites of Ministries of Education across Canada. Typically, these sites will contain data on the particular jurisdictions, information for parents and stakeholders,
} 
educational resources for teachers, administrative and planning tools for school board officials, and a description of policies, programs and initiatives.

${ }^{\mathrm{vi}}$ An illustration of the problem of not having a concrete, visible equity strategy could be the post-1995 period in Ontario, where there has been a flurry of accusations that school violence and gang activity have increased, in part because of a lack of focus on building school communities through social justice programs. There are many complexities to the problematic but it is clear that eliminating anti-racism from the formal educational map has made the task of ensuring that prevention and social cohesion, rather "zero tolerance" and "strict discipline", all the more difficult.

\section{Acknowledgements}

I would like to thank the two anonymous referees for the valuable comments they provided, and also acknowledge Gina Thésée for her input into the analysis in this paper through numerous discussions and collaborative projects. 